University of Nebraska - Lincoln

DigitalCommons@University of Nebraska - Lincoln

\title{
Tissue Stresses in Stented Coronary Arteries with Different Geometries: Effect of the Relation Between Stent Length and Lesion Length
}

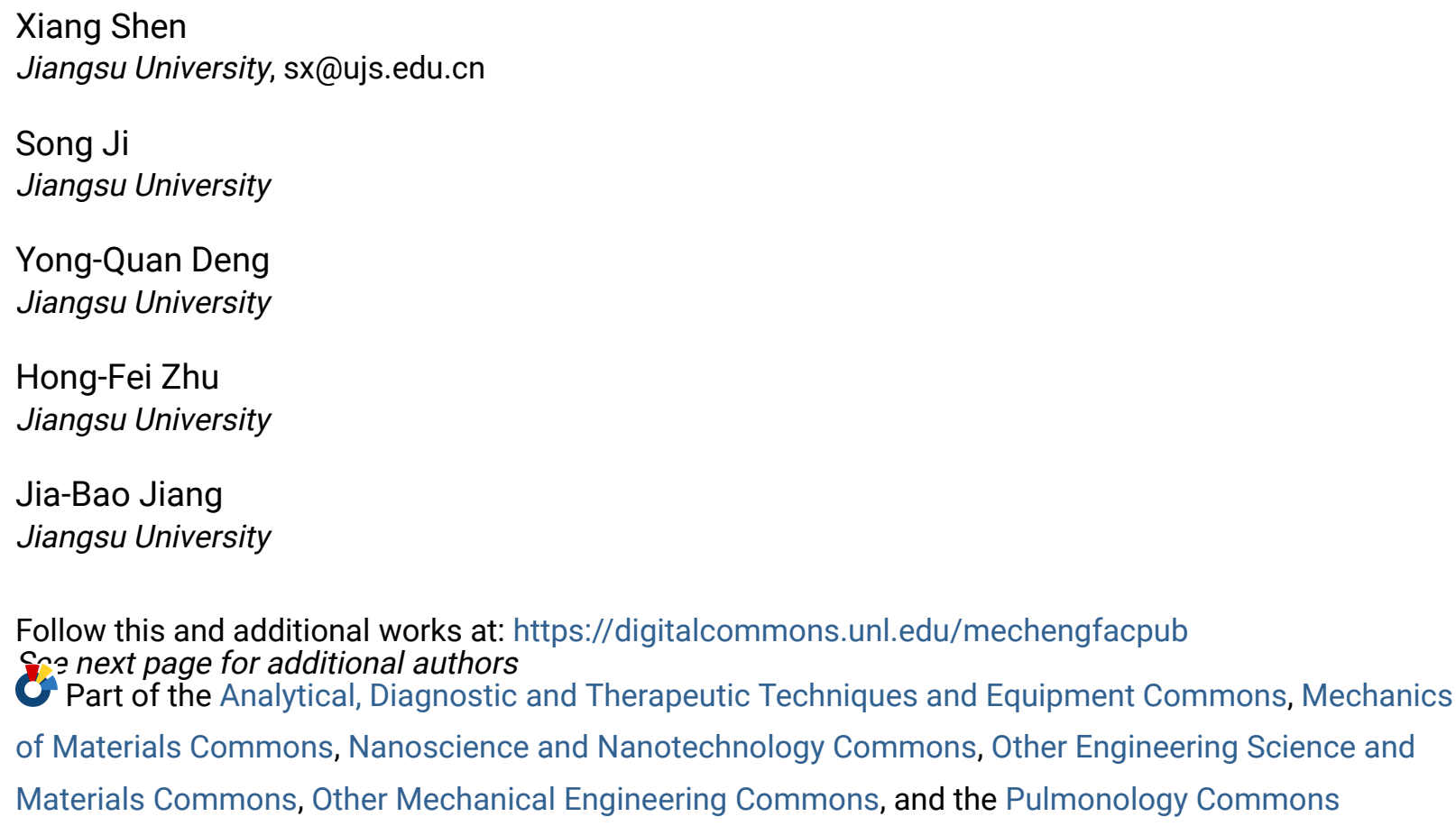

Shen, Xiang; Ji, Song; Deng, Yong-Quan; Zhu, Hong-Fei; Jiang, Jia-Bao; and Gu, Linxia, "Tissue Stresses in Stented Coronary Arteries with Different Geometries: Effect of the Relation Between Stent Length and Lesion Length" (2018). Mechanical \& Materials Engineering Faculty Publications. 322.

https://digitalcommons.unl.edu/mechengfacpub/322

This Article is brought to you for free and open access by the Mechanical \& Materials Engineering, Department of at DigitalCommons@University of Nebraska - Lincoln. It has been accepted for inclusion in Mechanical \& Materials Engineering Faculty Publications by an authorized administrator of DigitalCommons@University of Nebraska Lincoln. 


\section{Authors}

Xiang Shen, Song Ji, Yong-Quan Deng, Hong-Fei Zhu, Jia-Bao Jiang, and Linxia Gu 


\title{
Tissue Stresses in Stented Coronary Arteries with Different Geometries: Effect of the Relation Between Stent Length and Lesion Length
}

\author{
Xiang Shen, ${ }^{1}$ Song Ji, ${ }^{1}$ Yong-Quan Deng, ${ }^{1}$ Hong-Fei Zhu, ${ }^{1}$ \\ Jia-Bao Jiang, ${ }^{1}$ and Lin-Xia Gu${ }^{2}$ \\ 1 School of Mechanical Engineering, Jiangsu University, Zhenjiang 212013, China \\ 2 Department of Mechanical and Materials Engineering, \\ University of Nebraska-Lincoln, Lincoln, Nebraska, USA
}

Corresponding author - Xiang Shen, email sx@ujs.edu.cn

\begin{abstract}
In-stent restenosis after stent deployment remains an obstruction in the long-term benefits of stenting. This study sought to investigate the influence of the relation between stent length and lesion length on the mechanics of the arterial wall with different geometries, including straight and tapered vessels. Results showed that when the length of the stent was longer than the lesion length, the maximum stress in plaque and vessel increased as the length of stent increased. When the length of the stent was shorter than the lesion length, the vessel stress induced by stent inflation was lower; both ends of the stenosis plaque could not be fully expanded. When the length of the stent was equal to the lesion length, the plaque and vessel stress induced by stent inflation was minimal, and stent foreshortening was minimal. Compared with the straight vessel, the stent implantation in the tapered vessel with the same stent length resulted in greater stress in vessel and plaque, an increased stent recoil, and a decreased stent foreshortening. When the length of the stent is equal to lesion length, it may be the reasonable choice for straight vessels and tapered vessels. Conclusions drawn from this article can help surgeons to choose appropriate stent lengths.
\end{abstract}

Keywords: Vessel geometry, Stent length, Coronary stent, In-stent restenosis, Finite element analysis 


\section{Introduction}

Cardiovascular disease, a global healthcare problem and the major cause of death and disability, accounts for $30 \%$ of the world's deaths annually. Stent deployment is a common interventional procedure with high efficiency and minimal invasiveness compared with either angioplasty or coronary artery bypass surgery (Auricchio et al. 2015). However, clinical success after stent implantation is restricted by in-stent restenosis (ISR), a reduction in lumen diameter by neointima formation and stent thrombosis (ST) (Terzian et al. 2017; Kim and Dean 2011). Many researches have testified that ISR is caused by many factors, one of which is the high tissue stress induced by balloon dilation and stent implantation. Therefore, reducing the tissue stress and better understanding the stent expansion mechanism remain very meaningful in coronary intervention.

It is widely accepted that finite element analysis (FEA) is a powerful tool for computational modeling, revealing the structural response of the arterial walls during stent implantation (Eshghi et al. 2011; Imani et al. 2013a; Imani 2013). The factors that influence stent implantation involve the stent loading method (Imani et al. 2014), the stent structural design (Hara et al. 2006; Lally et al. 2005; Hsiao et al. 2012; Imani et al. 2013b, 2015), the wire stent fabrication technique (Zhao et al. 2012a), the material of the stent (Schiavone et al. 2014), and the plaque and vessel geometry (Dottori et al. 2016; Shen et al. 2014; Wei et al. 2016). A few researchers have used FEA to study the effect of these factors on stent and vascular mechanical properties (Gu et al. 2010; Hyre and Pulliam 2008; Cui et al. 2010; Zhao et al. 2012b). For example, Gu et al. (2010) used a computational model in which the length of the stent was longer than the lesion length to study the effect of stent structure and the level of stenosis on ISR. Hyre and Pulliam (2008) created a numerical model in which stent length was equal to lesion length to study the effects of the degree of balloon overhang and the type of plaque on arterial stress. Cui et al. (2010) generated a computational model in which stent length was shorter than lesion length to study the effects of balloon length and compliance on tissue stress. However, it is obvious that the selection of stent length is random in the above existing work. In the case of a given plaque length, the computational model they established was that the stent length was longer than the plaque length (Gu et al. 2010), or that the stent length was shorter than the plaque length (Cui et al. 2010), or that the stent length was equal to the plaque length (Hyre and Pulliam 2008).

In clinical study, for any given lesion, there is a high restenotic risk associated with longer bare metal stent lengths (Mauri et al. 2005). In randomized trials, longer drug-eluting stent (DES) length has been associated with adverse clinical events (Caputo et al. 2012). When the length of the stent was longer than the lesion length, Wong et al. (2005) studied the effect of 


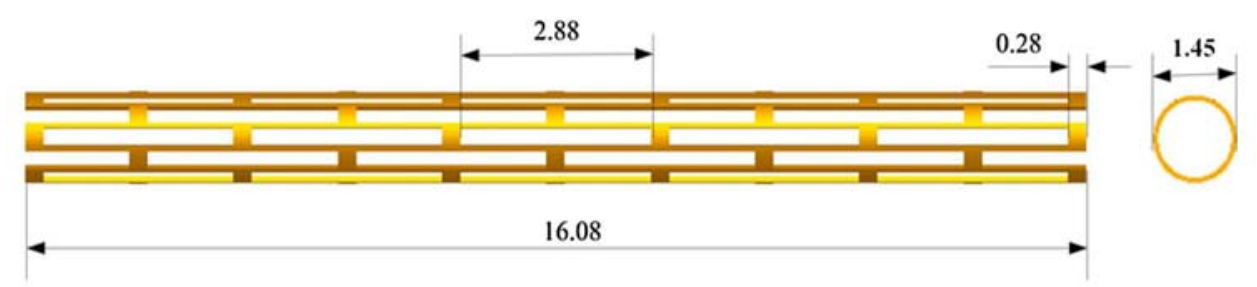

Fig. 1. Geometry of the stent.

the ratio of stent length to lesion length on clinical and angiographic restenosis after implantation of the stents. There has been limited analysis of the relation between the length of a target lesion and the chosen stent length to treat it. A systematic computational examination of the relationship between plaque length and stent length is lacking. Given an exact length of a narrow plaque, selecting the appropriate length of stent is of great significance. The aim of this paper is to investigate the effects of the relationship of the stent length with regard to lesion length on stent expansion and vessel biomechanical behavior. Conclusions drawn from this article may help interventional cardiologists to choose appropriate stent lengths. In order to get a reliable result, different vessel geometries, including straight vessels and tapered vessels, were considered.

\section{Materials and Methods}

\subsection{Geometric Models}

The balloon-expandable Palmaz-Schatz (PS) stent was investigated in this study. A coronary stent model was generated using commercial software Pro/Engineer Wildfire 5.0 (Fig. 1). Owing to the symmetry of the structure, only one-sixth of the stent was used to simulate the expansion process. The stent was $0.12 \mathrm{~mm}$ in thickness, with an outer diameter of $1.45 \mathrm{~mm}$. The PS stent consisted of six slots in the circumferential direction.

The diameter of the balloon was equal to the inner diameter of the stent. The balloon was $1 \mathrm{~mm}$ longer than the stent on each side. The straight plaque had a length of $12.92 \mathrm{~mm}$, inner diameter of $2 \mathrm{~mm}$, and thickness of $0.5 \mathrm{~mm}$. The straight vessel was $26 \mathrm{~mm}$ in length, with an inside diameter of $3 \mathrm{~mm}$, and a thickness of $0.5 \mathrm{~mm}$. For the tapered vessel and plaque, detailed data are shown in Table 1.

In this study, PS stent expansion in a coronary vessel was analyzed by considering different vessel geometries and stent lengths. By changing the length and the number of the slot, the total length of the stent was divided into three groups. Detailed data are summarized in Table 2. 
Table 1. Summary of dimensions for tapered artery models

\begin{tabular}{|c|c|c|c|c|c|c|}
\hline \multirow[t]{2}{*}{ Model } & \multirow[t]{2}{*}{ Tapering } & \multirow[t]{2}{*}{ Length $(\mathrm{mm})$} & \multicolumn{2}{|l|}{ Proximal end } & \multicolumn{2}{|l|}{ Distal end } \\
\hline & & & $\begin{array}{l}\text { Inner radius } \\
(\mathrm{mm})\end{array}$ & $\begin{array}{l}\text { Outer radius } \\
(\mathrm{mm})\end{array}$ & $\begin{array}{l}\text { Inner radius } \\
(\mathrm{mm})\end{array}$ & $\begin{array}{l}\text { Outer radius } \\
(\mathrm{mm})\end{array}$ \\
\hline Vessel & $0.43^{\circ}$ & 26 & 1.50 & 2.15 & 1.31 & 1.87 \\
\hline Plaque & $0.43^{\circ}$ & 12.92 & 1.44 & 1.00 & 1.35 & 0.94 \\
\hline
\end{tabular}

Table 2. Summary of dimensions for seven different stent models.

\begin{tabular}{lccc} 
Model & The total length $(\mathrm{mm})$ & The length of slot $(\mathrm{mm})$ & The number of slot \\
\hline$L_{0}$ & 16.08 & 2.88 & 5 \\
$L_{1}$ & 15.08 & 2.68 & 5 \\
$L_{2}$ & 14.08 & 2.48 & 5 \\
$M_{0}$ & 12.92 & 2.88 & 4 \\
$S_{2}$ & 11.92 & 2.63 & 4 \\
$S_{1}$ & 10.92 & 2.38 & 4 \\
$S_{0}$ & 9.76 & 2.88 & 3 \\
\hline
\end{tabular}

1. The length of the stent was longer than the lesion length of 1.16$3.16 \mathrm{~mm}$ with five slots in the axial direction and described as cases $\mathrm{L}_{0}, \mathrm{~L}_{1}$, and $\mathrm{L}_{2}$.

2. The length of the stent was equal to the lesion length, with four slots in the axial direction, and described as case $\mathrm{M}_{0}$.

3. The length of the stent was shorter than the lesion length of 1.00$3.16 \mathrm{~mm}$, with three or four slots in the axial direction, and described as cases $S_{0}, S_{1}$ and $S_{2}$.

The numerical results were compared in terms of stent radial recoil, foreshortening, stent deformation, and stress distribution in the artery and plaque induced by stent inflation.

\subsection{Meshing and Material Properties}

The balloon was simplified as a cylinder, which was meshed using quadrilateral elements with reduced integration (M3D4R), and the number of elements was 3107-4784, depending on the length of the balloon. The stent was meshed into hexahedral elements with reduced integration (C3D8R), and the number of elements to mesh the stent was 2772-4536, depending on the length of the stent. The eight-node linear brick, reduced integration 
elements with hourglass control (C3D8R), was used to mesh the artery and plaque, four layers of elements through the thickness. The coronary artery and plaque system had about 15,000 elements in total for all the simulations. The finite element models of the straight vessel and tapered vessel are demonstrated in Fig. 2.

The stent was made of $316 \mathrm{~L}$ stainless steel, which was modeled as a homogeneous, isotropic, elasto-plastic material with nonlinear hardening behavior. The stent had a Young's modulus of $201 \mathrm{GPa}$, a yield stress of 330 MPa, a Poisson's coefficient of 0.3 , and a limit stress of $750 \mathrm{MPa}$ (Liang et al. 2005). The material density was equal to $7.86 \mathrm{~g} / \mathrm{cm}^{3}$. The balloon was modeled using a linear elastic material with Young's modulus of 400,000 MPa, Poisson's coefficient of 0.3 (Gervaso et al. 2008). The coronary artery and stenotic plaque were modeled as an Ogden hyperelastic isotropic constitutive model. The Ogden hyperelastic strain energy potential is given by the following equation,

$$
W=\sum_{i=1}^{3} \frac{2 \mu_{i}}{\alpha_{i}^{2}}\left(\lambda_{1} \alpha_{i}+\lambda_{2} \alpha_{i}+\lambda_{3} \alpha_{i}-3\right)+\sum_{i=1}^{3} \frac{1}{D_{i}}(J-1)^{2 i}
$$

where $\lambda_{i}(i=1,2,3)$ are the principal stretches, and $\mu_{i}, \alpha_{i}$ and $D_{i}$ are the model parameters, which were adopted from the article (Schiavone et al. 2014). In this model, $\mu_{i}$ and $\alpha_{i}$ describe the shear behavior of the material and $D_{i}$ represents the compressibility. Detailed parameters are summarized in Table 3.

\subsection{Boundary Conditions and Loading}

Symmetric constraints were exerted on the corresponding symmetry planes of the stent, coronary artery, and stenotic plaque. The middle end of the stent was fixed, and the circumferential rotation was prohibited. In order to

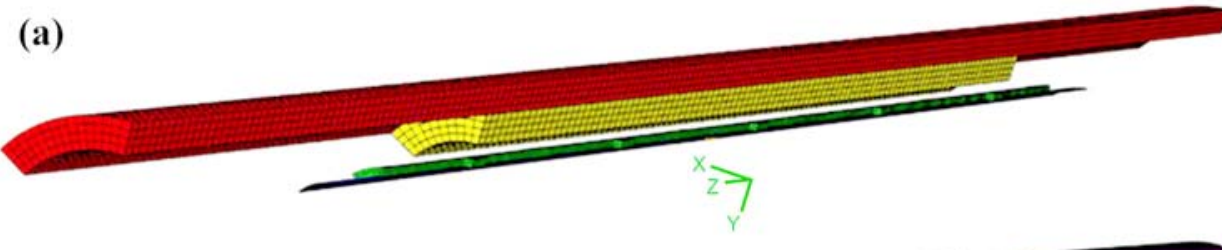

(b)

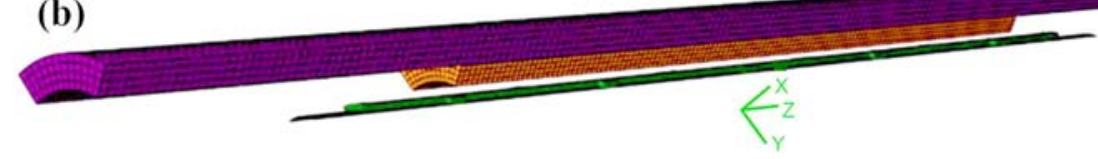

Fig. 2. Finite element models of a) straight vessel and b) tapered vessel. 
Table 3. Coefficients of the Ogden model used to describe the material behavior of the plaque and vessel.

\begin{tabular}{llrrrrrrr} 
Material & $\rho\left(\mathrm{kg} / \mathrm{mm}^{3}\right)$ & $\mu_{1}$ & $\mu_{2}$ & $\mu_{3}$ & $\alpha_{1}$ & $\alpha_{2}$ & $\alpha_{3}$ & $D_{1}$ \\
\hline Vessel & $1.066 \mathrm{E}-6$ & -1.23 & 0.88 & 0.45 & 16.59 & 16.65 & 16.50 & $5.31 \mathrm{E}-6$ \\
Plaque & $1.45 \mathrm{E}-6$ & 0.084 & - & - & 20.82 & - & $-2.70 \mathrm{E}-7$ \\
\hline
\end{tabular}

avoid rigid-body motions, the coronary artery and plaque were constrained in the circumferential direction and longitudinal direction on the symmetry planes. Both ends of the balloon were fully fixed to mimic the condition in relation to the catheter. All components were allowed to move only in a radial direction.

A uniform displacement load was applied to the inner surface of the balloon, so that the stent was dilated to the maximum outside diameter of $3.3 \mathrm{~mm}$. The stent deployment process was carried out using ABAQUS/Explicit solver, in which the inflation time was $30 \mathrm{~ms}$, and the deflation time was $20 \mathrm{~ms}$. For the sake of getting reasonable results, the kinetic energy of the whole analysis was monitored, and the ratio of kinetic energy and internal energy was less than 5-10\%. A finite-sliding, hard contact between the balloon's outer surface and the stent's inner surface was defined. There were five contact pairs between the balloon, stent, plaque, and blood vessels in total, and the friction coefficient was defined as 0.2 . The interfaces between artery and plaque were assumed to be coherent and considered as perfectly bonded.

\subsection{Post-processing of Results}

In this study, the stent radial recoil, foreshortening, and maximum stress in the artery-plaque system at the end of the deflation step were defined as follows,

$$
\begin{gathered}
\text { Stent tapering }=\left(D_{\text {pro }}-D_{\text {dis }}\right)=D_{\text {pro }} \times 100 \% \\
\text { Stent recoil }=\left(D_{0}-D_{1}\right)=D_{0} \times 100 \% \\
\text { Stent foreshortening }=\left(L-L_{\text {deflation }}\right) / L \times 100 \%
\end{gathered}
$$

where $D_{\text {pro }}$ and $D_{\text {dis }}$ are the proximal and distal diameters of the stent after expansion, respectively. $L$ and $L_{\text {deflation }}$ are the initial and final lengths of the stent, respectively. $D_{0}$ and $D_{1}$ are the initial and ultimate lengths of the stent, respectively. 


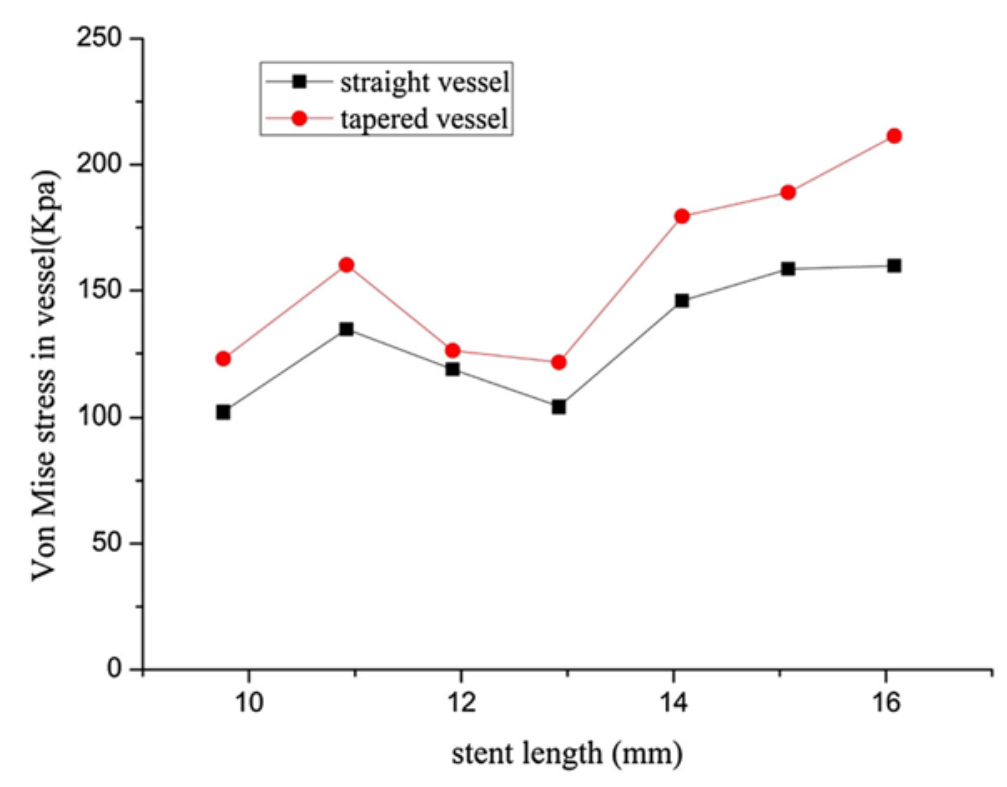

Fig. 3. Von Mises stress in vessel with different stent lengths.

\section{Results}

3.1 Effect of the Relation Between Stent Length and Lesion Length on Arterial Mechanics

Following the stent expansion to the nominal diameter, the stress distribution in the vessel is shown in Fig. 3. The maximum Von Mises stress in the vessel was $104 \mathrm{Kpa}$ in case $M_{0}$ after stent deflation. However, the vascular stress in case $L_{0}$ increased by $60 \%$ compared with case $M_{0}$. In the tapered vessel, after comparing case $L_{0}$ and case $M_{0}$, it was shown that an increase in stent length from 11.92 to $16.08 \mathrm{~mm}$ resulted in an increase in vessel stress from 121.5 to $211.4 \mathrm{Kpa}$. The vascular stress in cases $S_{0}$ and $M_{0}$ was lowest whenever the stent was dilated in a straight vessel or a tapered vessel. When the length of the stent was longer than the lesion length, the maximum stress in the vessel increased as the length of stent increased.

The Von Mises stress distribution in straight and tapered vessels in cases $\mathrm{S}_{0}, \mathrm{M}_{0}$, and $\mathrm{L}_{0}$ is shown in Fig. 4. Compared with the straight vessel, the stentinduced stress in the tapered vessel was larger when the stent with same length was used. In all the simulations, the highest vessel stresses were localized in the areas which were close to the distal/proximal end of the stenosis plaque. A potential injury to the vessel might occur at these critical zones. For the tapered vessel, greater stress in the distal end of the vessel was observed. 
(a)

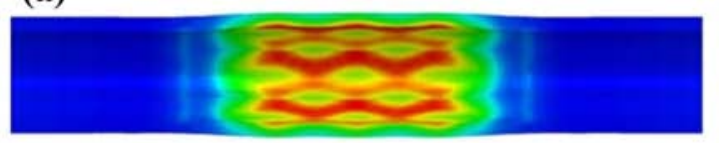

(b)

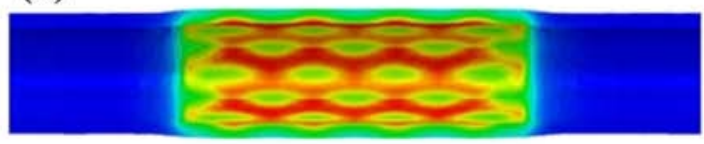

(c)

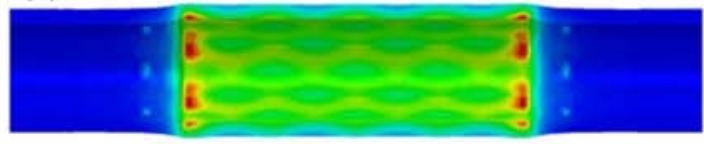

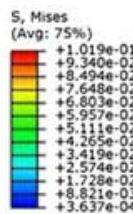
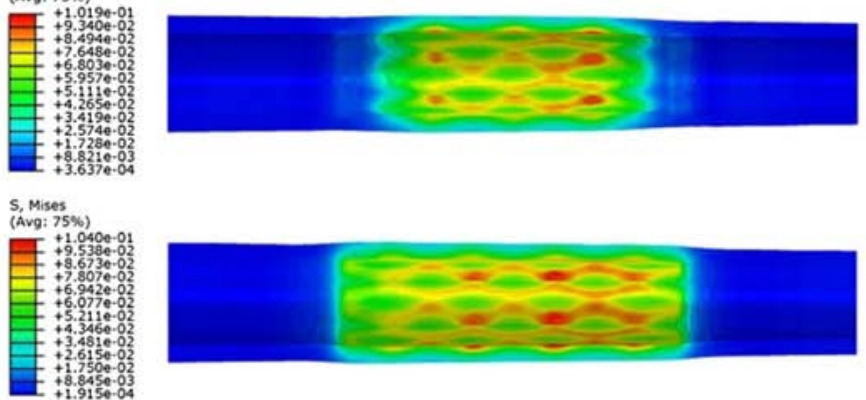

S, Mises
(Avg: $75 \%$ )
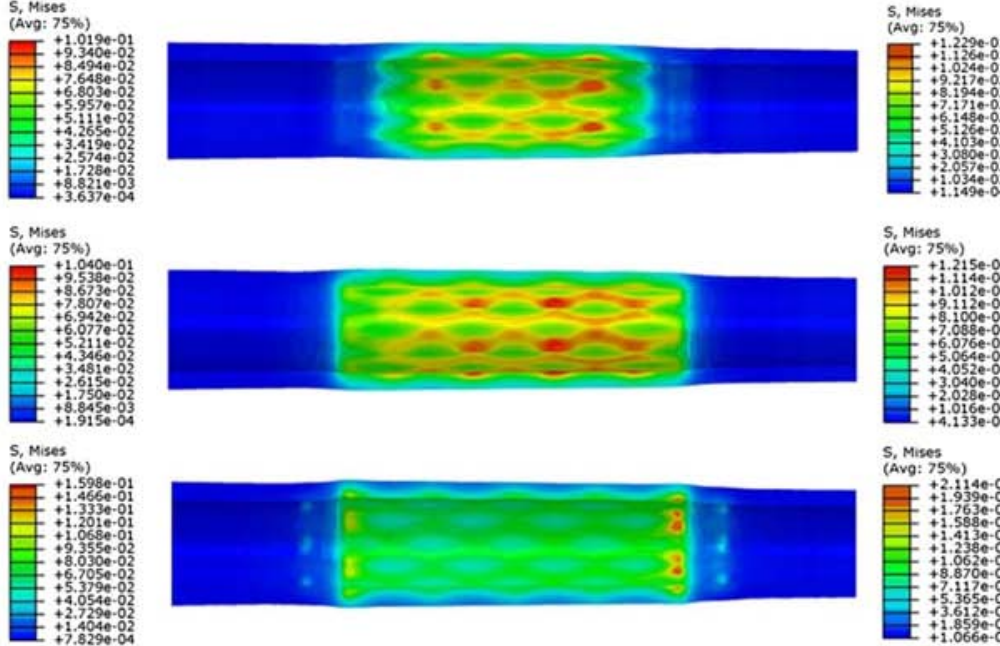

S, Mises
(Avg: $75 \%$ )

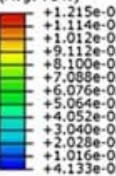

S, Mises

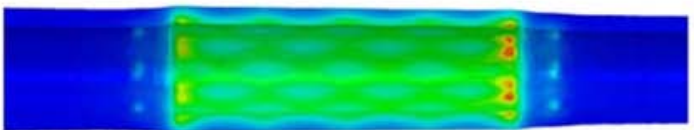

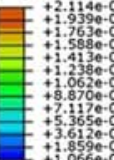

Fig. 4. Von Mises stress distribution in straight vessel (left) and tapered vessel (right) following stent expansion in a) $S 0$ model; b) $M_{0}$ model; c) $L_{0}$ model.

\subsection{Effect of the Relation Between Stent Length and Lesion Length on Plaque Deformation}

After stent expansion, the stress distribution in the plaque is shown in Fig. 5. The level of the stent length had a significant impact on the stress of the plaques. For instance, the maximum Von Mises stress in the tapered

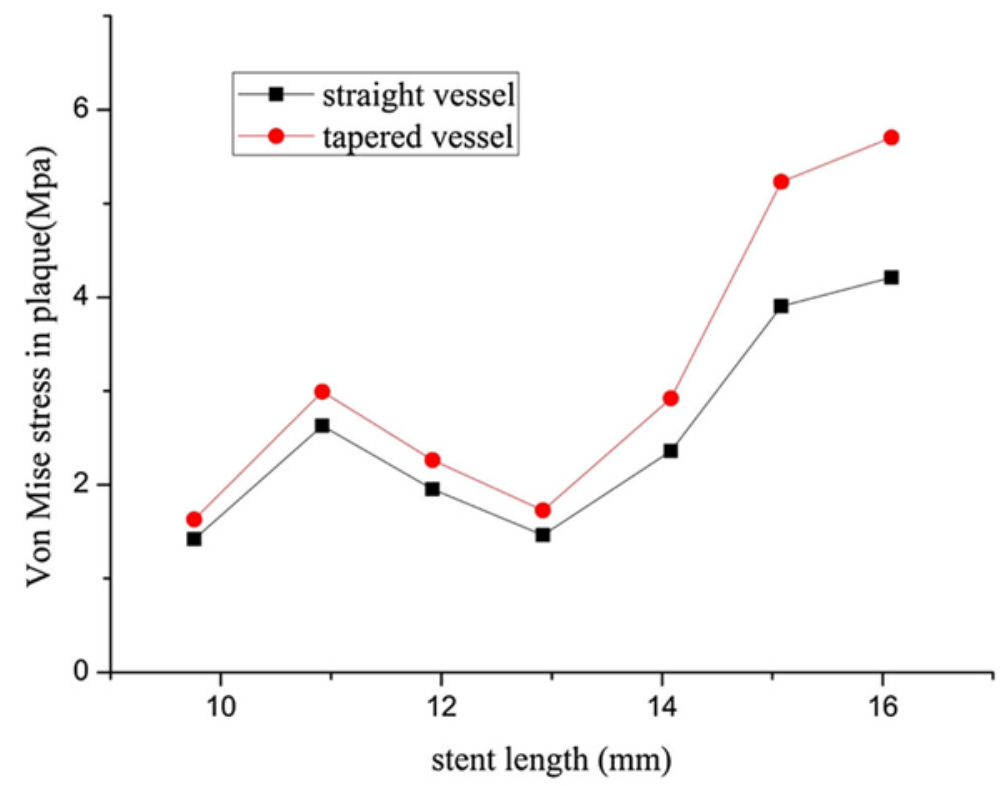

Fig. 5. Von Mises stress in plaque with different stent lengths. 
(a)

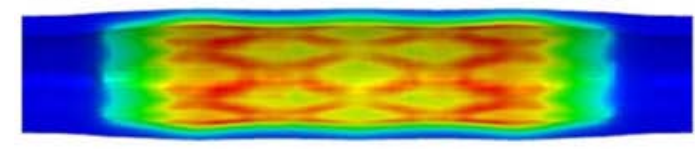

(b)

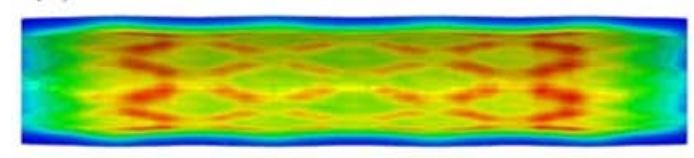

(c)

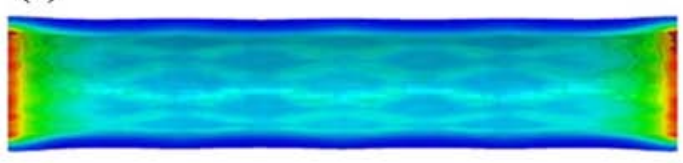

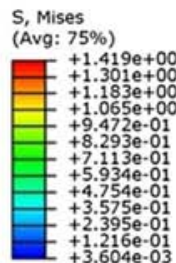
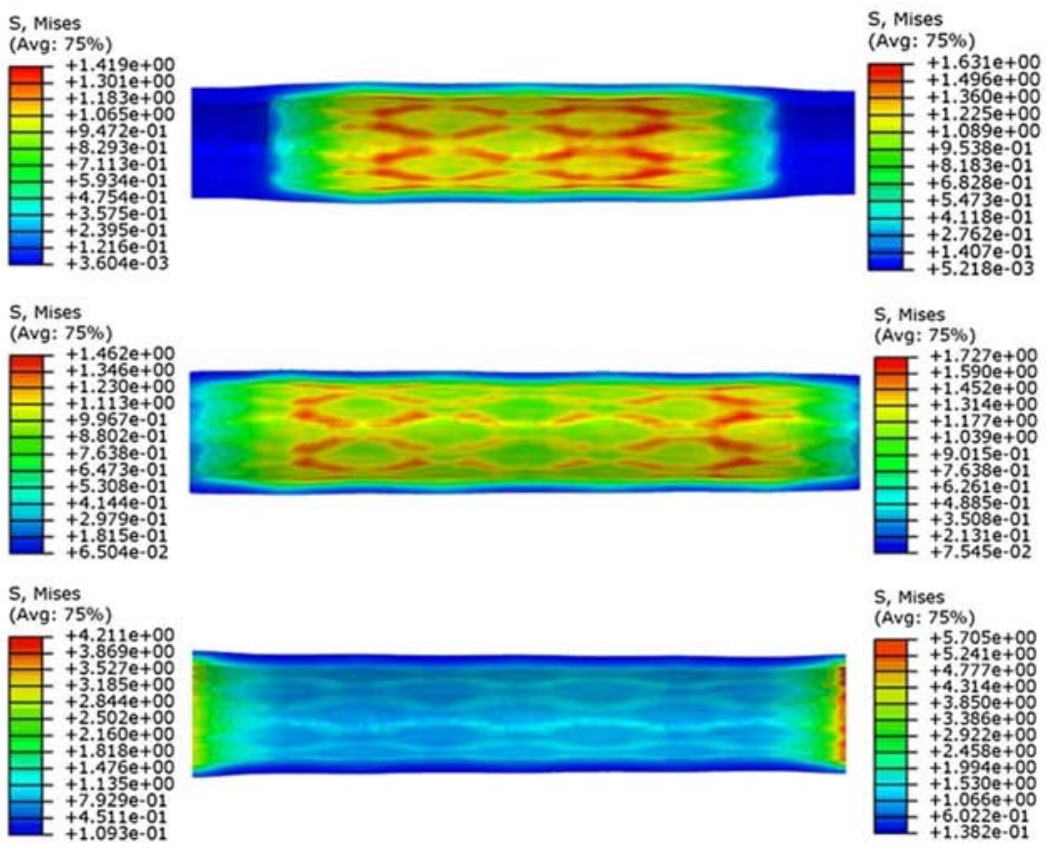

Fig. 6. Von Mises stress in straight plaque (left) and tapered plaque (right) following stent expansion in a) $S_{0}$ model; b) $M_{0}$ model; c) $L_{0}$ model.

plaque was $5.70 \mathrm{Mpa}$ in case $L_{0}$, which was $9.6,97$, and $235 \%$ larger than cases $S_{1}, S_{2}$, and $M_{0}$, respectively. It is worth noting that the plaque stress in cases $S_{0}$ and $M_{0}$ was lowest. When the length of the stent was longer than the lesion length, the maximum stress in the plaque increased as the length of stent increased.

The Von Mises stress distribution in straight and tapered plaques in cases $S_{0}, M_{0}$ and $L_{0}$ is presented in Fig. 6 . The length of the stent was shorter than the lesion length as was in case $S_{0}$. The minimum stress was localized in the distal/ proximal end of the plaque, in which the radial displacement of the plaque following expansion was minimal. This indicated that both ends of the plaque could not be fully expanded. When the length of the stent was longer than the lesion length, the maximum stress was localized in the distal/proximal end of the plaque where the stent and the plaque were directly in contact.

\subsection{Effect of the Relation Between Stent Length and Lesion Length on Stent Deformation}

As shown in Fig. 7, when the length of the stent was equal to the lesion length, the stent foreshortening was minimal, which indicates that the stent 


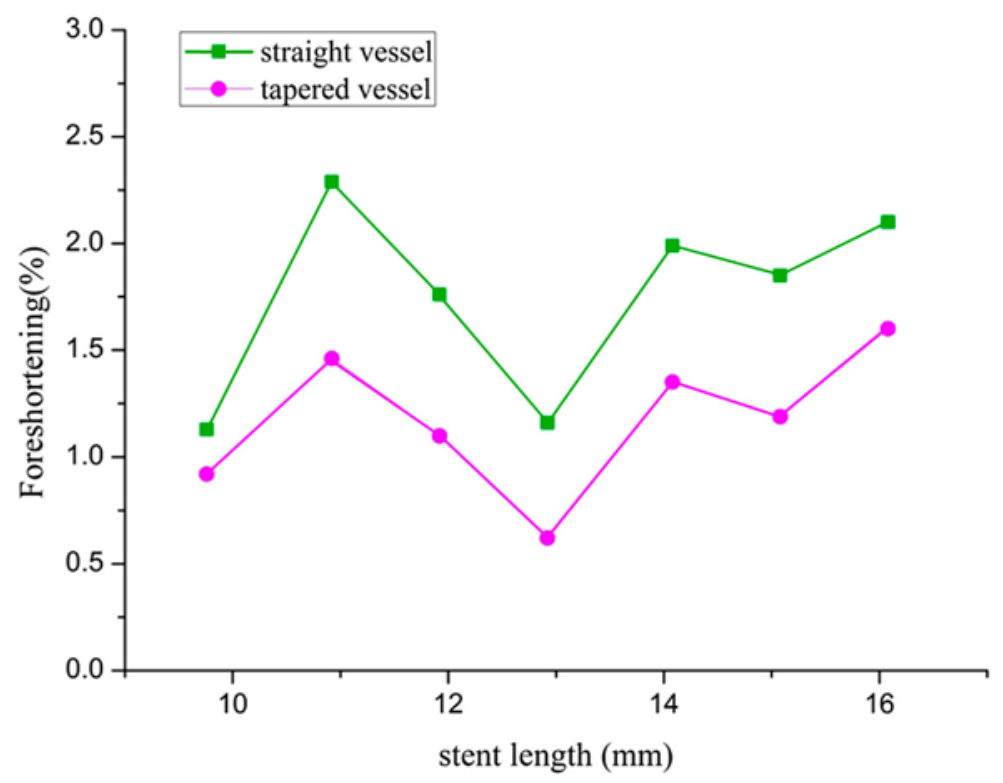

Fig. 7. Stent foreshortening with different stent lengths.

with this length can cover the stenosis plaque. In the straight vessel, the stent foreshortening in $L_{0}$ model increased by $81 \%$ compared with $M_{0}$ model. Compared with the straight vessel, the stent foreshortening decreased after stent implantation in the tapered vessel.

As shown in Fig. 8, the outer diameter of the middle of the stent was less than the distal in the case $L_{0}$. This phenomenon may be explained by the fact that the severely stretched vessel-plaque system at the middle section, having a stronger tendency to recover its original shape, exerted pressure on the stent, causing more recoil at the middle part during the end of the deflation process, which was the "dog-boning" effect. When the length of the stent was shorter than the lesion length, the stent recoil was nearly uniform.

As shown in Fig. 9, the outer diameter of the stent gradually decreased from its proximal end to its distal end after deflation. When stent length was shorter than $14.08 \mathrm{~mm}$, the stent tapering increased with the length of stent increasing. The stent tapering in the cases $S_{0}, S_{1}, S_{2}, M_{0}$, and $L_{1}$ was 3.3, 3.6, $4.4,4.5$, and $5.5 \%$, respectively. The areas of maximum stress in the stent after expansion were concentrated in the corners of the diamond cells of the stent. When the length of the stent was longer than $14.08 \mathrm{~mm}$, both ends of the stent recoil were less than the middle of the stent. Compared with the straight vessel, the stent recoil increased after stent implantation in the tapered vessel. 


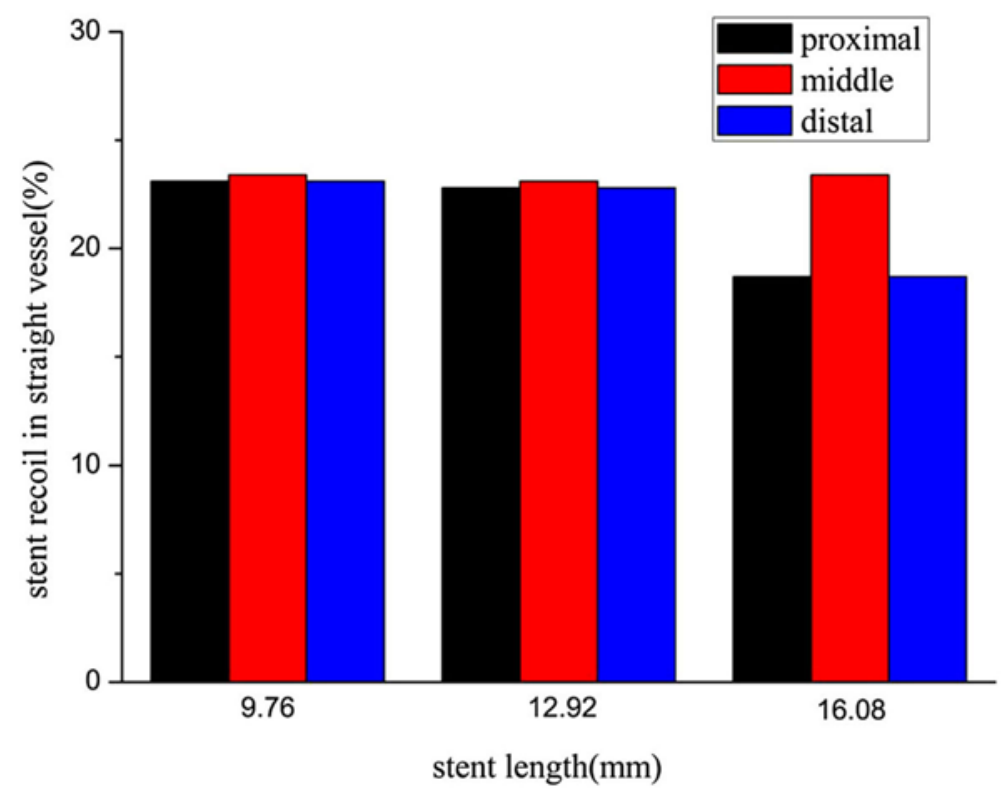

Fig. 8. Stent recoil in straight vessel with different stent lengths.

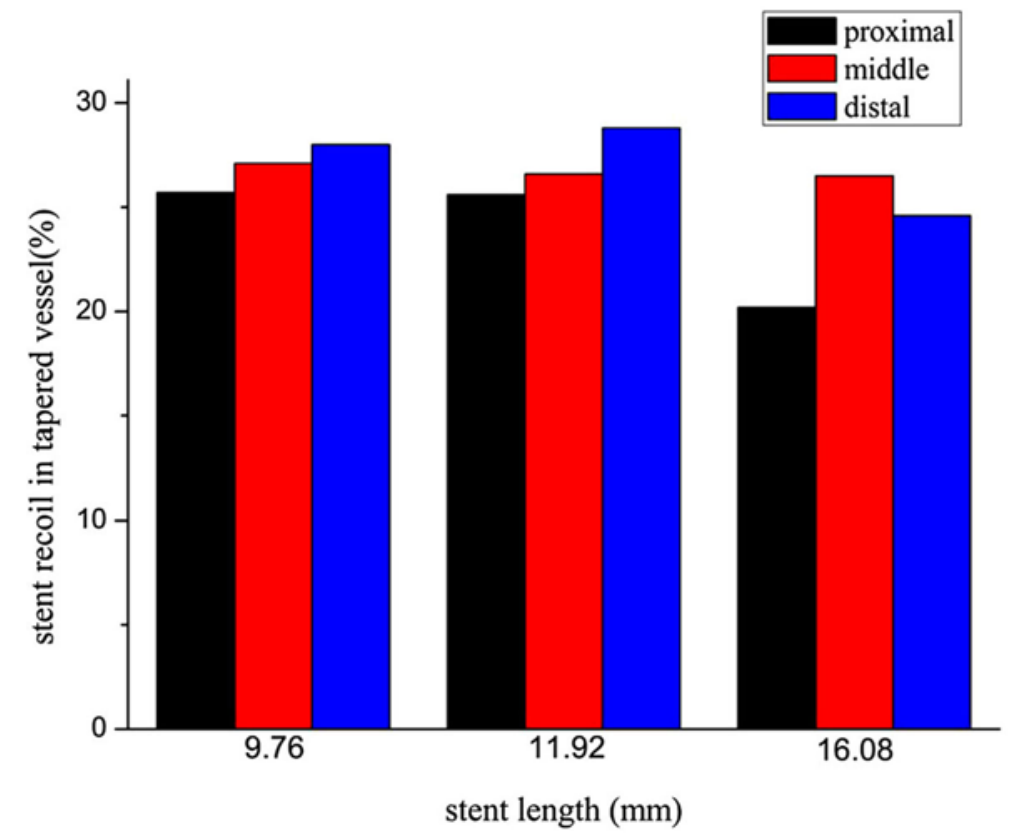

Fig. 9. Stent recoil in tapered vessel with different stent lengths. 


\section{Discussions}

In clinical studies, numerous researchers have studied the effect of stent length on clinical outcome. A clinical report has shown that when DES was longer than $31.5 \mathrm{~mm}$, higher rates of ST and mortality were observed (Suh et al. 2010). Foley et al. (2001) studied that the length of the stent was associated with angiographic restenosis and major adverse cardiovascular events when the length of the stent was longer than the lesion area length of 4-8 $\mathrm{mm}$ and divided into five groups. Zbinden et al. (2017) analyzed the influence of stent length and stent diameter on ISR and showed that when stent diameter is greater than $3.0 \mathrm{~mm}$ and lesion length is less than $15 \mathrm{~mm}$, it was worth recommending to use DES instead of bare metal stents (BMS). Kasaoka et al. (1998) found that minimizing the total stent length may reduce in-stent restenosis during the procedure.

In numerical simulation, when the length of the stent was longer than the lesion length, Imani et al. investigated the stent structural design and loading method on arterial biomechanical behavior. He found that the plaque had a nonuniform deformation in the radial direction. At the same time, the diameter at the end sides was larger than that of the middle of the stent (Imani et al. 2013b, 2014), which was in agreement with our work.

In this paper, the effect of different stent lengths and vessel geometry has been investigated by means of the finite element method. A digital model of stent expansion in tapered vessels and straight vessels has been developed to evaluate whether the relationship of the stent length with regard to lesion length may be significant when choosing a stent in clinical practice. The Von Mises stress level could serve as the indicator of plaque rupture and vessel damage.

When the length of the stent was longer than the lesion length, the stent could cover the diseased coronary artery. However, it also resulted in greater stress in the plaque and vessel after stent expansion. This result agreed with the clinical research that the longer stent resulted in a greater rate of restenosis (Foley et al. 2001; Kasaoka et al. 1998). When the length of the stent was shorter than the lesion length, the vessel stress induced by stent inflation was lower. Nevertheless, both ends of the stenosis plaque could not be fully expanded.

Compared with the straight vessel, the stent implantation in the tapered vessel with the same stent length resulted in greater vessel and plaque stress, and the Von Mises stress of the plaque-artery system gradually increased from its proximal end to its distal end during stent expansion. The result showed good agreement with the findings of the numerical simulation study (Shen et al. 2014). The result also indicated an increased stent recoil and a decreased stent foreshortening after the stent implantation in 
the tapered vessel. Meanwhile, when the length of the stent was greater than the lesion length, the incomplete stent apposition was observed at the proximal end of the artery. This might imply ST events as well as ISR (Dottori et al. 2016).

In order to reduce the occurrence of ISR and stent thrombosis, the plaque-vessel system stress caused by stent expansion should be considered. Fortunately, when the length of the stent is equal to the lesion length, this stent length can achieve a trade-off between the stent longer than lesion length and the stent shorter than lesion length, resulting in an acceptable plaque-vessel system stress. Furthermore, this stent length is also associated with the lowest attainable restenosis rate (Mauri et al. 2004). At the same time, the longer bare metal stent lengths resulting in a high restenotic rate. The longer DES length has been associated with adverse clinical events (Mauri et al. 2005; Caputo et al. 2012).Therefore, when the length of the stent is equal to the lesion length, it may be the reasonable choice for straight and tapered vessels.

\section{Conclusions}

In the present work, the accurate digital model is reconstructed, and the numerical simulation of stent implantation is carried out in detail. Different vessel geometries and the length of the stent are taken into consideration to explore the stent expansion mechanism, and the main conclusions are as following:

The effect of the stent length has shown, in fact, that a length change about $1 \mathrm{~mm}$ corresponds to very large amplitudes for the Von Mises stress. When the length of the stent is longer than lesion length, the maximum stress in plaque and vessel increased as the length of stent increased. The study showed that vessel geometry has a significant effect on arterial stress. Stent expansion in tapered vessels resulted in greater plaque and vessel stress, and an increased stent recoil and a decreased stent foreshortening.

When the length of the stent was equal to the lesion length, the plaque and vessel stress induced by stent inflation were minimal, and the stent foreshortening was minimal. This indicated that the stent may cover the diseased artery. Therefore, the length of the stent was equal to lesion length, which may be the reasonable choice for straight vessels and tapered vessels. The result provides some useful proof which may be used for clinicians to make lifesaving decisions and choose appropriate stent lengths. 
Acknowledgments - This project is supported by the National Natural Science Foundation of China (51305171), Natural Science Foundation of Jiangsu Province (BK20130525), Natural Science Foundation of the Higher Education Institutions of Jiangsu Province (13KJB460006), China Postdoctoral Science Foundation (2011M500858), Foundation of Jiangsu University (10JDG123), and Project of Jiangsu University for training young backbone teachers.

\section{References}

Auricchio F, Constantinescu A, Conti M et al (2015) A computational approach for the lifetime prediction of cardiovascular balloon-expandable stents. Int J Fatigue 75:69-79

Caputo RP, Goel A, Pencina M et al (2012) Impact of drug eluting stent length on outcomes of percutaneous coronary intervention (from the EVENT registry). Am J Cardiol 110(3):350-355

Cui FS, Lee HP, Lu C et al (2010) Effects of balloon length and compliance on vascular stent expansion. Int J Appl Mech 2(03):681-697

Dottori S, Flamini V, Vairo G (2016) Mechanical behavior of peripheral stents and stent-vessel interaction: a computational study. Int J Comput Methods Eng Sci Mech 17(3):196-210

Eshghi N, Hojjati MH, Imani M et al (2011) Finite element analysis of mechanical behaviors of coronary stent. Proc Eng 10:3056-3061

Foley DP, Pieper M, Wijns W et al (2001) The influence of stent length on clinical and angiographic outcome in patients undergoing elective stenting for native coronary artery lesions; final results of the Magic $5 \mathrm{~L}$ Study. Eur Heart J 22(17):1585-1593

Gervaso F, Capelli C, Petrini L et al (2008) On the effects of different strategies in modelling balloon-expandable stenting by means of finite element method. J Biomech 41(6):1206-1212

Gu L, Zhao S, Muttyam AK et al (2010) The relation between the arterial stress and restenosis rate after coronary stenting. J Med Dev 4(3):031005

Hara H, Nakamura M, Palmaz JC et al (2006) Role of stent design and coatings on restenosis and thrombosis. Adv Drug Deliv Rev 58(3):377-386

Hsiao HM, Chiu YH, Lee KH, Lin CH (2012) Computational modeling of effects of intravascular stent design on key mechanical and hemodynamic behavior. Comput Aided Des 44(8):757-765

Hyre MR, Pulliam RM (2008) Balloon/stent expansion dynamics in stenotic arteries. ASME 2008 international mechanical engineering congress and exposition. American Society of Mechanical Engineers, pp 565-573

Imani M (2013) Simulation of mechanical behaviors of NIR stent in a stenotic artery using finite element method. World Appl Sci J 22(7):892-897

Imani M, Goudarzi AM, Hojjati MH (2013a) Finite element analysis of mechanical behaviors of multi-link stent in a coronary artery with plaque. World Appl Sci J 3(21):1600-1601 
Imani M, Goudarzi AM, Ganji DD et al (2013b) The comprehensive finite element model for stenting: The influence of stent design on the outcome after coronary stent placement. J Theor Appl Mech 51(3):639-648

Imani SM, Goudarzi AM, Ghasemi SE et al (2014) Analysis of the stent expansion in a stenosed artery using finite element method: Application to stent versus stent study. Proc Inst Mech Eng Part H J Eng Med 228(10):996-1004

Imani SM, Goudarzi AM, Valipour P, Barzegar M, Mahdinejad J, Ghasemi SE (2015) Application of finite element method to comparing the NIR stent with the multi-link stent for narrowings in coronary arteries. Acta Mech Solida Sin 28(5):605-612

Kasaoka S, Tobis JM, Akiyama T et al (1998) Angiographic and intravascular ultrasound predictors of in-stent restenosis. J Am Coll Cardiol 32(6):1630-1635

Kim MS, Dean LS (2011) In-stent restenosis. Cardiovasc Ther 29(3):190-198

Lally C, Dolan F, Prendergast PJ (2005) Cardiovascular stent design and vessel stresses: A finite element analysis. J Biomech 38(8):1574-1581

Liang DK, Yang DZ, Qi M et al (2005) Finite element analysis of the implantation of a balloon-expandable stent in a stenosed artery. Int J Cardiol 104(3):314-318

Mauri L, O'Malley AJ, Cutlip DE et al (2004) Effects of stent length and lesion length on coronary restenosis. Am J Cardiol 93(11):1340-1346

Mauri L, O'Malley AJ, Popma JJ et al (2005) Comparison of thrombosis and restenosis risk from stent length of sirolimus-eluting stents versus bare metal stents. Am J Cardiol 95(10):1140-1145

Schiavone A, Zhao LG, Abdel-Wahab AA (2014) Effects of material, coating, design and plaque composition on stent deployment inside a stenotic artery-Finite element simulation. Mater Sci Eng C 42:479-488

Shen X, Xie ZM, Sun YY et al (2014) Balloon-expandable stents expansion in tapered vessels and their interactions. J Mech Med Biol 14(06):1440013

Suh J, Park DW, Lee JY et al (2010) The relationship and threshold of stent length with regard to risk of stent thrombosis after drug-eluting stent implantation. JACC Cardiovasc Interv 3(4):383-389

Terzian Z, Gasser TC, Blackwell F et al (2017) Peristrut microhemorrhages: A possible cause of in-stent neoatherosclerosis? Cardiovasc Pathol 26:30-38

Wei L, Chen Q, Li Z (2016) Study on the impact of straight stents on arteries with different curvatures. J Mech Med Biol 16(07):1650093

Wong SC, Hong MK, Ellis SG et al (2005) Influence of stent length to lesion length ratio on angiographic and clinical outcomes after implantation of bare metal and drug-eluting stents (the TAXUSIV Study). Am J Cardiol 95(9):1043-1048

Zbinden R, Felten S, Wein B et al (2017) Impact of stent diameter and length on in-stent restenosis after DES vs BMS implantation in patients needing large coronary stents-A clinical and health-economic evaluation. Cardiovasc Ther 35(1):19-25

Zhao S, Liu XC, Gu L (2012a) The impact of wire stent fabrication technique on the performance of stent placement. J Med Dev 6(1):011007

Zhao S, Gu L, Froemming SR (2012b) Performance of self-expanding Nitinol stent in a curved artery: Impact of stent length and deployment orientation. J Biomech Eng 134(7):071007 